\title{
Biomarkers and aspects in acute stroke
}

\section{Biomarcadores e ASPECTS no AVC agudo}

José Manuel FERRO'1,2

\author{
${ }^{1}$ Centro Hospitalar Lisboa \\ Norte, Hospital Santa Maria, \\ Departamento de Neurociências \\ e Saúde Mental, Serviço de \\ Neurologia, Lisboa, Portugal. \\ ¿Universidade de Lisboa, Faculdade \\ de Medicina, Instituto de Medicina \\ Molecular, Lisboa, Portugal. \\ José Manuel FERRO (D https:// \\ orcid.org/0000-0002-2343-9097 \\ Correspondence: José Manuel \\ Ferro; E-mail:jmferro@medicina. \\ ulisboa.pt \\ Conflict of interest: There is no \\ conflict of interest to declare. \\ Received on April 20, 2020; Received \\ in its final form on April 20, 2020; \\ Accepted on April 22, 2020.
}

I $\mathrm{n}$ the last decades there was a surge of research on serum haematological, biochemical and immunological biomarkers in stroke, which unfortunately has not yet translated into clinical practice. Serum biomarkers can theoretically be useful for the diagnosis, prognosis, and understanding of the pathophysiology and eventually for the selection of treatments in stroke care. Ideally a biomarker or a set of biomarkers can identify a stroke, in the prehospital setting, prior to neuroimaging, similarly to what is done for myocardial infarction ${ }^{1,2}$. Several other molecules can be useful biomarkers of recanalization and reperfusion, of opening of collaterals, of the several steps of the ischemic cascade and of the early neuroinflammatory and neuroregenerative response ${ }^{3,4}$. Inflammatory molecules might become both biomarkers and therapeutic targets for stroke management ${ }^{5}$.

In this issue of Arquivos de Neuro-Psiquiatria, Aline M. Mourão and co-workers conducted an exploratory cross-sectional study of the clinical and molecular correlates of the ASPECTS scale score in the 50 patients within the first $24 \mathrm{~h}$ of acute stroke ${ }^{6}$. They measured several biomarkers mainly related to inflammation (BDNF, VCAM-1, VEGF, IL-1 $\beta$, sTNFRs and adiponectin) and correlated their values with the score in the ASPECTS, a well-known and validated scale to grade the extent of an acute ischemic infarct as depicted on non-contrast brain CT. They found an association of adiponectin levels and ASPECTS scores. On regression analysis, adiponectin and NIHSS were independent predictors of ASPECTS scores.

Adiponectin is an anti-inflammatory adipokine, which also has anti-atherosclerotic properties. Elevated adiponectin levels indicating an intense inflammatory response are an independent predictor of cardiovascular and all-cause mortality in patients with coronary heart disease $^{7}$. Adiponectin levels do not appear to be related to stroke risk ${ }^{8,9}$.

This exploratory study has a very promising and innovative result, by establishing an association between adiponectin levels and acute infarct size. Previous studies have described associations between high levels of adiponectin and stroke mortality, neurological severity as measured by the NIHSS and functional outcome $\mathrm{e}^{10,11,12}$.

As the authors themselves recognise in the final part of the discussion, their study has several limitations, including cross-sectional design, no evaluation of mortality and functional status at 3 or 6 months, small sample size with young median age, selection bias, multiple statistical comparisons, and using linear regression for scale scores. As they also point, further confirmatory studies are needed. Nevertheless, adiponectin looks like to be a promising biomarker for stroke severity and outcome. Mourão et al. findings may be also an additional reason for not stopping statins in acute stroke patients ${ }^{13}$.

\section{References}

1. Monbailliu T, Goossens J, Hachimi-Idrissi S. Blood protein biomarkers as diagnostic tool for ischemic stroke: a systematic review. Biomark Med. 2017 May;11(6):503-12. https://doi.org/10.2217/bmm-2016-0232

2. Perry LA, Lucarelli T, Penny-Dimri JC, McInnes MD, Mondello S, Bustamante A, et al. Glial fibrillary acidic protein for the early diagnosis of intracerebral hemorrhage: Systematic review and meta-analysis of diagnostic test accuracy. Int J Stroke. 2019 Jun;14(4):390-9. https://doi.org/10.1177/1747493018806167

3. Hotter B, Hoffmann S, UIm L, Montaner J, Bustamante A, Meisel C, et al. Inflammatory and stress markers predicting pneumonia, outcome, and etiology in patients with stroke: Biomarkers for predicting pneumonia, functional outcome, and death after stroke. Neurol Neuroimmunol Neuroinflamm. 2020 Feb;7(3):e692. https:// doi.org/10.1212/NXI.0000000000000692 
4. Bustamante A, Simats A, Vilar-Bergua A, García-Berrocoso T, Montaner J. Blood/brain biomarkers of inflammation after stroke and their association with outcome: from c-reactive protein to damage-associated molecular patterns. Neurotherapeutics. 2016 Oct;13(4):671-84. https://doi.org/10.1007/s13311-016-0470-2

5. Ramiro L, Simats A, García-Berrocoso T, Montaner J. Inflammatory molecules might become both biomarkers and therapeutic targets for stroke management. Ther Adv Neurol Disord. 2018 Aug 6;11:1756286418789340. https://doi. org/10.1177/1756286418789340

6. Mourão AM, Vicente LCC, Abreu MNS, Sant'Anna RV, De Meira FCA Xavier RMB, et al. Clinical and molecular correlates of the ASPECTS in the acute phase of stroke. Arq Neuropsiquiatr. 2020. In press.

Yang L, Li B, Zhao Y, Zhang Z. Adiponectin and incident coronary heart disease and stroke. A systematic review and meta-analysis of prospective studies. Lipids Health Dis. 2019 Dec;18(1):227. https:// doi.org/10.1186/s12944-019-1168-3

8. Kanhai DA, Kranendonk ME, Uiterwaal CS, van der GraafY, Kappelle LJ, Visseren FL. Prognostic value of adiponectin level in patients with coronary artery disease: a systematic review and meta-analysis. Obes Rev. 2013 Jul;14(7):555-67. https://doi.org/10.1111/obr.12027
9. Bouziana S, Tziomalos K, Goulas A, Hatzitolios Al. The role of adipokines in ischemic stroke risk stratification. Int J Stroke. 2016 Jun;11(4):389-98. https://doi.org/10.1177/1747493016632249

10. Nagasawa H, Yokota C, Toyoda K, Ito A, Minematsu K. High level of plasma adiponectin in acute stroke patients is associated with stroke mortality. J Neurol Sci. 2011 May;304(1-2):102-6. https://doi. org/10.1016/j.jns.2011.02.002

11. Wang Z, Li B, Wang Y, Maimaitili A, Qin H, Dangmurenjiafu G, Wang S. The association between serum adiponectin and 3-month outcome after ischemic stroke. Cardiovasc Diabetol. 2019 Aug;18(1):105. https://doi.org/10.1186/s12933-019-0908-z

12. Kuwashiro T, Ago T, Kamouchi M, Matsuo R, Hata J, Kuroda $J$, et al. Significance of plasma adiponectin for diagnosis, neurological severity and functional outcome in ischemic stroke - Research for Biomarkers in Ischemic Stroke (REBIOS). Metabolism. 2014 Sep;63(9):1093-103. https://doi.org/10.1016/j. metabol.2014.04.012

13. Gasbarrino K, Hafiane A, Zheng H, Daskalopoulou SS. Intensive statin therapy compromises the adiponectin-adipoR pathway in the human monocyte-macrophage lineage. Stroke. 2019 Dec;50(12):3609-617. https://doi.org/10.1161/STROKEAHA.119.026280 